\title{
p-Dimethylaminobenzaldehyde: preliminary investigations into a novel reagent for the detection of latent fingermarks on paper surfaces
}

\author{
Patrick Fritz, ${ }^{a}$ Wilhelm van Bronswijk ${ }^{a}$ and Simon W. Lewis $*^{a}$
}

\begin{abstract}
5 A new method for the detection of latent fingermarks on paper surfaces using $p$ -
dimethylaminobenzaldehyde (DMAB) is described. The method is based upon the reaction of DMAB

with the amino acids present in the latent finger mark to give a yellow-brown impression that is

photoluminescent when illuminated with a high intensity filtered light source at $490 \mathrm{~nm}$ and viewed

through orange goggles (OG550). A wet contact method proved effective on non-fragile porous substrates

10 such as white photocopy paper and various other substrates, while a dry contact (solventless) method

afforded development on thermal paper. Luminescence spectrophotometry of developed L-alanine,

glycine and L-serine spots on paper was used to confirm that DMAB were reacting with amino acids in

the latent fingermark.
\end{abstract}

\section{Introduction}

15 Fingermarks remain an important and reliable means of personal identification and as such not only establish whether contact at an incident scene has occurred, but can also link an individual to a crime ${ }^{1}$. The ability to analyse the ridge patterns of a latent (invisible) fingermark depends on the ability to first detect it, and 20 a range of chemical and physical techniques have been developed to enable this ${ }^{1-3}$. The visualisation of latent fingermarks surfaces by chemical means can be considered to be the trace detection of the various biomolecules from the skin secretions which make up latent impression where their spatial distribution needs to be 25 retained for subsequent analysis ${ }^{4}$. Fingermark detection chemistry shares with other areas of analytical chemistry the constant search for improved selectivity and sensitivity in order to maximise the number and quality of latent fingermarks detected on exhibits ${ }^{5-8}$. The substrate upon which a latent 30 fingermark is deposited has a significant influence on the the detection technique applied ${ }^{3,9}$. Detection methods that target amino acids present in latent fingermark deposits have achieved widespread use for paper surfaces due to the strong and stable binding of free amino acids, derived from eccrine sweat, onto 35 cellulose fibres resulting in a good representation of the fingermark ${ }^{4,10-12}$.

p-Dimethylaminobenzaldehyde (DMAB) is utilised in histochemical studies to visualise amino acids and other amines in-situ through both colour and photoluminescence ${ }^{13-17}$. This

40 reveals a potential for use of this compound as the basis for a development technique for latent fingermarks, both through its ability to produce photoluminescent products with the target analytes but also the maintenance of spatial integrity, which is essential for fingermark identification. As DMAB is also used 45 extensively on micro-organisms such as bacteria, it is therefore likely to be able to reveal fingermark ridges with sufficient detail as the deposits that form these may only be a few micrometres in diameter ${ }^{17}$.

DMAB is structurely closely related to $p$ 50 dimethylaminocinnamaldehyde (DMAC), which has previously been investigated for its application to the detection of latent fingermarks on paper surfaces ${ }^{18,19}$. First studied in the mid- 1970s by Morris, it was a novel technique that was thought to show promise as a ninhydrin alternative ${ }^{18}$. However, an in depth 55 study conducted by Sasson and Almog found that the method was inferior to ninhydrin on nearly all fingermark samples tested ${ }^{19}$. A significant issue encountered was that fingermarks that were treated 72 hours after deposition appeared blurred. This was thought to be due to urea (the proposed target compound) 60 migrating rapidly through porous substrates ${ }^{2,19}$. It has since been established that DMAC does not exclusively target urea in fingermark deposits; it also reacts with primary and secondary amines, including amino acids ${ }^{2,19}$. It is not clear why DMAC is unable to detect aged fingermarks as other amino acid sensitive 65 reagents, such as ninhydrin or 1,2-indanedione, can successfully treat fingermarks a significant time after deposition ${ }^{4}$. Because of its lower sensitivity compared to ninhydrin, and its inability to reliably develop aged prints, DMAC has not since been pursued as an alternative fingermark reagent ${ }^{19}$.

70 DMAB has been recently been reported in relation to the detection of latent fingermarks, by its use in a procedure for the visualisation of cyanoacrylate fumed fingermarks ${ }^{20}$. The researchers proposed that DMAB stains the polymer layer that forms on the fingermark during the fuming process and can 75 therefore offer luminescent detail, there is no discussion of reactions with amino acids or amines that may be present ${ }^{20}$. To the best of our knowledge, DMAB has not been used as a treatment reagent for the development of latent fingermarks on paper surfaces.

80 Here we present our preliminary studies into the application of p-dimethylaminobenzaldehyde as reagent for the detection of latent fingermarks on paper surfaces. The aim of the study was to develop a method for the treatment of latent fingermarks with DMAB and to explore its advantages and limitations. ${ }_{85}$ Furthermore, its ability to be used on fingermarks that had been left in ambient conditions for extended periods after deposition was investigated, as well as its use in sequence with other treatment methods. 


\section{Materials and Methods}

\section{Chemicals}

1,2-Indanedione (CASALI/Optimum Technology, Australia), absolute ethanol (CSR chemicals, Australia), L-alanine (BDH, 5 Australia), anhydrous zinc chloride (BDH, USA), citric acid (Ajax Finechem, Australia), ethyl acetate (Univar analytical, Australia), ferric nitrate nonahydrate (Chem-Supply, Australia), ferrous ammonium sulphate hexahydrate (Sigma-Aldrich, USA), glacial acetic acid (CSR chemicals, Australia), glycine (BDH, 10 Australia), HFE-7100 TM (1-methoxynonafluorobutane, 3M Novec, Australia), hydrochloric acid (Ajax Finechem, Australia), maleic acid (Sigma-Aldrich, USA), methanol (Mallinckrodt, USA), n-dodecylamine acetate (Optimum Technology, Australia), Oil Red O (Sigma-Aldrich, USA), $p$ 15 dimethylaminobenzaldehyde (BDH, USA), petroleum spirits 40$60{ }^{\circ} \mathrm{C}$ and $60-80{ }^{\circ} \mathrm{C}$ (APS chemicals, Australia), propylene glycol (Sigma-Aldrich, USA), L-serine (Sigma-Aldrich, USA), silver nitrate (Chem-Supply, Australia), sulfuric acid (Ajax Finechem, Australia) and Tween 20 (Sigma-Aldrich, Australia) 20 were all used as received and were of analytical reagent grade unless otherwise stated.

\section{Collection of latent fingermarks}

Latent fingermarks were collected on white copy paper (Fuji Xerox Professional) from 2-10 donors per experiment.

25 Fingermark donors had not consumed food or handled chemicals for at least 30 minutes before providing samples. The hands were rubbed together prior to depositing fingermarks to offer consistent natural, uncharged fingermarks for all samples unless otherwise stated. For charged fingermarks containing sebaceous 30 secretions, donors were asked to rub their fingers on their face or hair immediately prior to collection. Donors were instructed to gently place fingertips onto the substrate, which were outlined in graphite pencil (less than 10 seconds overall deposition time). Samples were treated within 24-36 hours following deposition.

\section{${ }_{35}$ Preparation of reagent solutions}

The preparation of stock and working solutions for both DMAB formulations is summarised in Table 1.

To prepare the treatment papers for the dry contact DMAB method, the white A4 copy paper or chromatography paper 40 (Whatman No.1) was dipped into the working solution and allowed to air dry before being stored in a sealed zip-lock plastic bag.

Wet contact 1,2-indanedione/zinc chloride (IND/ $\mathrm{ZnCl}_{2}$ ) reagent was prepared as recommended by the Australian Federal ${ }_{45}$ Police (AFP) ${ }^{4,21-23}$.
Table 1 Preparation of stock and working solutions

\begin{tabular}{|c|c|c|}
\hline & Solution & Reagent Preparation \\
\hline $\begin{array}{l}\text { Wet Contact } \\
\text { DMAB }\end{array}$ & $\begin{array}{l}\text { DMAB stock } \\
\text { solution } \\
\text { Working } \\
\text { solution }\end{array}$ & $\begin{array}{c}1 \mathrm{~g} \text { DMAB in } 22 \mathrm{~mL} \text { ethyl acetate and } 3 \\
\text { mL acetic acid } \\
1 \mathrm{~mL} \text { stock solution diluted with } 9 \mathrm{~mL} \\
\text { HFE-7100 }\end{array}$ \\
\hline $\begin{array}{l}\text { Dry Contact } \\
\text { DMAB }\end{array}$ & $\begin{array}{l}\text { Working } \\
\text { solution }\end{array}$ & 4 g DMAB in $100 \mathrm{~mL}$ ethyl acetate \\
\hline \multirow[t]{3}{*}{$\begin{array}{l}\text { Wet Contact } \\
\text { IND/ZnCl }\end{array}$} & $\begin{array}{l}\text { IND stock } \\
\text { solution }\end{array}$ & $\begin{array}{l}4 \mathrm{~g} \text { 1,2-indanedione dissolved in } 450 \mathrm{~mL} \\
\text { ethyl acetate and } 50 \mathrm{~mL} \text { glacial acetic } \\
\text { acid }\end{array}$ \\
\hline & $\begin{array}{l}\mathrm{ZnCl}_{2} \text { stock } \\
\text { solution }\end{array}$ & $\begin{array}{c}8 \mathrm{~g} \text { zinc chloride dissolved in } 200 \mathrm{~mL} \\
\text { absolute ethanol }\end{array}$ \\
\hline & $\begin{array}{l}\text { Working } \\
\text { solution }\end{array}$ & $\begin{array}{c}2 \mathrm{~mL} \text { zinc chloride stock solution and } 50 \\
\mathrm{~mL} \text { stock solution added to } 450 \mathrm{~mL} \\
\text { HFE-7100 solvent }\end{array}$ \\
\hline \multirow[t]{2}{*}{ 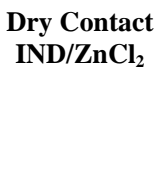 } & $\begin{array}{c}1,2- \\
\text { indanedione } \\
\text { stock solution }\end{array}$ & $\begin{array}{l}0.75 \mathrm{~g} \text { 1,2-indanedione and } 20 \mathrm{mg} \mathrm{ZnCl}_{2} \\
\text { dissolved in } 0.5 \mathrm{~mL} \text { ethanol, } 15 \mathrm{~mL} \\
\text { dichloromethane and } 35 \mathrm{~mL} \text { ethyl } \\
\text { acetate }\end{array}$ \\
\hline & $\begin{array}{l}\text { Working } \\
\text { solution }\end{array}$ & $\begin{array}{l}5 \mathrm{~mL} \text { stock solution added to } 45 \mathrm{~mL} \\
\text { HFE-7100 or } 45 \mathrm{~mL} \text { petroleum spirits }\end{array}$ \\
\hline \multirow[t]{5}{*}{$\begin{array}{l}\text { Physical } \\
\text { Developer }\end{array}$} & $\begin{array}{l}\text { Detergent- } \\
\text { surfactant } \\
\text { solution }\end{array}$ & $\begin{array}{c}0.5 \mathrm{~g} \text { n-dodecylamine acetate and } 0.5 \mathrm{~g} \\
\text { Tween } 20 \text { dissolved in } 125 \mathrm{~mL} \\
\text { deionised water }\end{array}$ \\
\hline & Redox solution & $\begin{array}{l}7.5 \mathrm{~g} \text { ferric nitrate nonahydrate, } 20 \mathrm{~g} \\
\text { ferrous ammonium sulphate } \\
\text { hexahydrate, } 5 \text { g citric acid and } 10 \mathrm{~mL} \\
\text { detergent-surfactant solution dissolved } \\
\text { in } 225 \mathrm{~mL} \text { deionised water in order } \\
\text { given }\end{array}$ \\
\hline & $\begin{array}{l}\text { Silver nitrate } \\
\text { solution }\end{array}$ & $\begin{array}{c}10 \mathrm{~g} \text { silver nitrate dissolved in } 50 \mathrm{~mL} \\
\text { deionised water }\end{array}$ \\
\hline & $\begin{array}{l}\text { Maleic acid } \\
\text { pre-wash }\end{array}$ & $\begin{array}{c}6.25 \text { g maleic acid dissolved in } 250 \mathrm{~L} \\
\text { deionised water }\end{array}$ \\
\hline & $\begin{array}{l}\text { Working } \\
\text { solution }\end{array}$ & $\begin{array}{l}7.5 \mathrm{~mL} \text { silver nitrate stock solution } \\
\text { added to } 142.5 \mathrm{~mL} \text { redox stock solution }\end{array}$ \\
\hline Oil Red O & $\begin{array}{l}\text { Working } \\
\text { solution }\end{array}$ & $\begin{array}{l}0.05 \text { g ORO dissolved in } 100 \mathrm{~mL} \\
\text { propylene glycol at } 95^{\circ} \mathrm{C} \text { with constant } \\
\text { stirring. Cooled solution is vacuum } \\
\text { filtered before use }\end{array}$ \\
\hline
\end{tabular}

Dry contact 1,2-indanedione (IND) reagent was prepared as 50 described by Patton et al. with two formulations, one containing HFE-7100 and another containing petroleum spirits, being used ${ }^{22}$. White A4 copy paper was dipped in the working solution, air dried and stored in a sealed zip-lock plastic bag to produce the treatment papers.

55 The Oil red O (ORO) reagent was prepared as described by Frick et al. ${ }^{24}$. The stain solution was stored at room temperature in Schott bottles wrapped in aluminium foil.

Physical developer (PD) stock and working solutions were prepared as recommended by the AFP ${ }^{21}$, with a modification as 60 described by Sauzier et al., where Tween 20 was substituted for Synperonic N. ${ }^{25}$. The PD working solution was prepared fresh as needed, and only used twice before discarding.

\section{Development of latent fingermarks using the DMAB methods}

In the final wet contact DMAB treatment, the samples were 65 immersed into the working solution for 1-2 seconds before being air dried at room temperature and heated in an oven (Zhicheng ZRD-A5055) at $150^{\circ} \mathrm{C}$ for 20 minutes.

In the final dry contact method, the samples were either placed between treatment papers in an Elna laundry press at high 
temperature for 45 seconds (non-fragile samples) or in a zip-lock bag for 2 days (fragile samples).

\section{Development of latent fingermarks using the IND methods}

Samples developed with the conventional wet contact ${ }_{5} \mathrm{IND} / \mathrm{ZnCl}_{2}$ method were dipped briefly in the working solution, and allowed to air dry before being heat treated for 10 seconds with an Elna laundry press (set at $\left.160^{\circ} \mathrm{C}\right)^{21}$.

Dry contact IND treatment was carried out as described by Patton et al. ${ }^{22}$. Samples were sandwiched between two treatment 10 papers and stored in a zip-lock plastic bag for at least 24-36 hours in the dark, with no heat being applied.

\section{Development of latent fingermarks using ORO}

Samples were placed in a glass tray and immersed in the ORO reagent for 15 minutes, with manual agitation provided by 15 gently rocking the tray for 30 seconds at the beginning of treatment, according to Frick et al. ${ }^{24}$. After development, ORO treated samples were rinsed twice in a deionised water bath under running water, and air dried on paper towels at room temperature.

\section{${ }_{20}$ Development of latent fingermarks using PD}

Apart from one minor modification, where the maleic acid pretreatment step was increased from 5 minutes to 30 minutes as recommended by Salama et al., the procedure used was as described by the AFP ${ }^{21,26}$. Samples were rinsed in deionised 25 water for 10 minutes, immersed in maleic acid for 30 minutes, then rinsed again in deionised water for 10 minutes. They were then submerged into the working solution for up to 20 minutes. After development was achieved, samples were rinsed several times in deionised water and air dried on paper towels at room 30 temperature away from direct light. Each step was carried out in a separate glass tray.

\section{Amino acid spot tests}

Solutions of L-Serine, L-alanine and glycine amino acid spot were prepared in water at concentrations of $15 \mu \mathrm{g} / \mu \mathrm{L}$ and 0.15

$35 \mu \mathrm{g} / \mu \mathrm{L}$. $10 \mu \mathrm{L}$ was dispensed onto plain white photocopy paper and allowed to air dry. The amino acid spots were then treated with the wet contact DMAB method as described above.

\section{Luminescence Photospectrometry}

Luminescence spectra were obtained using a Cary Eclipse 40 Fluorescence Spectrophotometer with a fibre optic probe attachment (Varian, Mulgrave, Australia). Data was recorded as an average of 10 scans and with excitation and emission slit widths of $5 \mathrm{~nm}$.

\section{Photography of samples}

${ }_{45}$ Samples were photographed using a Nikon D300 camera, equipped with an AF-S Micro-Nikkor lens, mounted on a Firenze Mini Repro tripod and connected to a computer using Nikon's Camera Control Pro Version 2.0.0. Illumination in luminescence mode was achieved using a Rofin Polilight ${ }^{\circledR}$ PL500 (Rofin, 50 Australia), with an excitation wavelength of $490 \mathrm{~nm}$ (and $505 \mathrm{~nm}$ for IND comparisons) and an orange camera filter attachment (550 nm barrier filter). Illumination in absorbance mode was achieved using incandescent light bulbs with no camera filter attachments. See Table 4 for a summary of the photographic 55 conditions. Later adjustments of the images were performed on Adobe Photoshop CS5 Version 12.1, only for clarity of the figures in this article. Evaluation of the fingermark development was carried out on raw images.

Table 4 Photographic conditions for absorbance and luminescence mode 60 photographs.

\begin{tabular}{ccc} 
& Absorbance mode & Luminescence mode \\
Focal Length/mm & 60 & 60 \\
Exposure Mode & Manual & Manual \\
White Balance & Auto & Auto \\
Shutter Speed/s & $1 / 20$ & 1 \\
Aperture & $\mathrm{f} / 11$ & $\mathrm{f} / 11$ \\
Sensitivity & ISO 200 & ISO 200 \\
\hline
\end{tabular}

\section{Results and Discussion}

The reaction that occurs between DMAB and primary amine groups has been widely studied in the biological field ${ }^{13-16}$. This is called an imine or Schiff base formation and occurs in acidic 65 conditions, where the acid protonates the slightly basic DMAB molecule to initiate the reaction. It is generally accepted that a working solution $\mathrm{pH}$ of $4-5$ provides the best reaction rate ${ }^{27,28}$. DMAB bonds to the nitrogen in primary amine groups, such as amino acids and urea and the general reaction mechanism can be 70 seen in Fig. 1. DMAB can also react with secondary amines to produce enamines, where the reaction pathway is identical to the imine formation except that a proton is lost from the carbon instead of the nitrogen ${ }^{28}$.



75 Fig. 1 General reaction mechanism for the imine formation from primary amines and DMAB (adapted from Adegoke \& Nwoke, 2008) ${ }^{29}$.

A formulation of $1 \mathrm{~g}$ DMAB in 60:40 mL of ethanol/water, which is referred to as Ehrlich's Reagent, is used for histological studies ${ }^{13}$. To test whether DMAB had any potential as a 80 fingermark detection reagent, latent fingermrks deposited on paper were treated with a Ehrlich's Reagent formulation of $1 \mathrm{~g}$ DMAB in $100 \mathrm{~mL}$ ethanol and heated for 10 seconds in an Elna laundry press on high heat. Faint brown impressions were oberved which were weakly photoluminescent when illuminated 85 at $490 \mathrm{~nm}$ and viewed through an orange filter (OG550), indicating that DMAB was reacting with the fingermark deposits on the paper. 


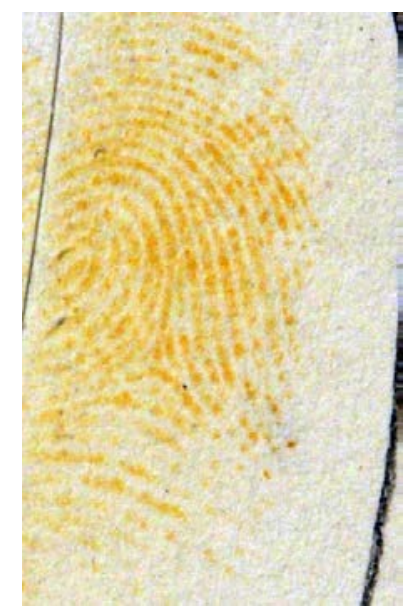

Fig. 2 Fingermark treated with DMAB working solution. Photograph taken with a Nikon D300 camera in absorbance mode; focal length: 60 mm, shutter speed: $1 / 20$ second and aperture: $\mathrm{f} / 11$.

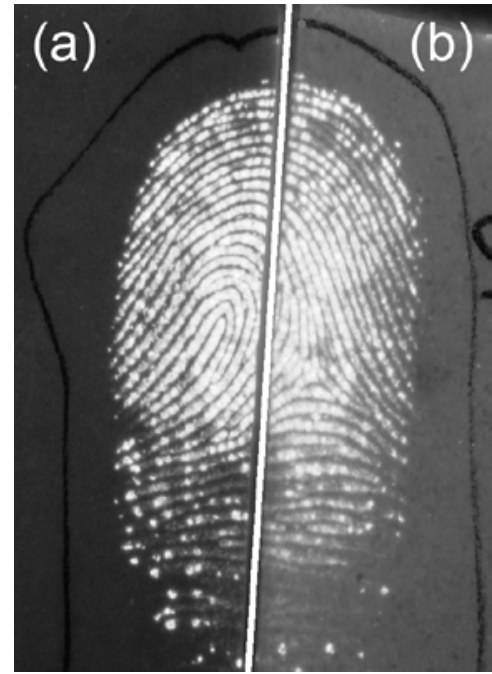

Fig. 3 Fingermark treated with (a) $1 \mathrm{~mL}$ of stock solution (1 g DMAB in $22 \mathrm{~mL}$ ethyl acetate and $0.5 \mathrm{~mL}$ acetic acid) in $9 \mathrm{~mL}$ HFE-7100 and (b) $0.6 \mathrm{~g}$ DMAB in $49.5 \mathrm{~mL}$ ethyl acetate and $0.5 \mathrm{~mL}$ acetic acid. Photograph taken with a Nikon D300 camera in luminescence mode; focal length: 60 10 $\mathrm{mm}$, shutter speed: 1 second and aperture: $\mathrm{f} / 11$.

\section{Method Development}

Typically latent fingermarks on paper are developed by immersing the paper exhibit into a solution of the relevant reagent, drying by evaporation of the solvent and in some cases 15 heating ${ }^{1-3}$. For amino acid sensitive reagents a wide variety of solvents have been used, with an ideal solvent being volatile (so as to faciltate drying time), non-toxic and non-polar. This last feature is important to avoid the running of ink on documents ${ }^{30}$. In addition co-solvents may be required to assist dissolution of 20 the reagent in the non-polar carrier solvent. The presence of acids and metal salts have also been shown to improve performance for some treatments ${ }^{4}$.

A variety of solvents that have been applied to fingermark reagent formulation (acetone, ethanol, ethyl acetate, HFE-7100, 25 methanol, petroleum spirits $\left(40-60{ }^{\circ} \mathrm{C}\right.$ and $\left.60-80{ }^{\circ} \mathrm{C}\right)$ and propylene glycol) were investigated for their performance in relation to fingermark development, minimisation of damage to the exhibit, and the effect on tsequencing with other treatment options. A range of DMAB concentrations (0.4, 0.8, 1.2, 2.4 and $304.8 \mathrm{~g} / 100 \mathrm{~mL}$ ) and a variety of acids (citric, glacial acetic, maleic, nitric, sulfuric and hydrochloric acids) at varying concentrations (0.018-3.5 M) were examined in combination with the carrier solvent. It was found that the choice of acid had a much greater effect than the choice of solvent. For example, although acetone 35 and ethanol were inferior to methanol and ethyl acetate, some fingermark development could still be obtained. However, using an unsuitable acid (such as sulfuric, maleic or citric acid) resulted in very faint or no development at all. It was found that a formulation consisting of DMAB in ethyl acetate and glacial 40 acetic acid gave yellow brown fingermarks (Fig. 2) which exhibited photoluminescence when illuminated at $490 \mathrm{~nm}$ with a high intensity filtered light source and viewed through an orange filter (OG550).

However a formulation based solely on ethyl acetate as the ${ }_{45}$ carrier would be unsuitable for operational use as this would cause issues with the running of ink on written documents. DMAB is insoluble in non-polar solvents (such as petroleum spirits and HFE-7100), however it was found that a stock solution of DMAB in ethyl acetate and acetic acid, could be added to 50 HFE-7100 to yield a working solution that could successfully develop latent fingermarks (Fig. 3). The ratio of DMAB: acid: ethyl acetate was adjusted to improve the response of the reagent in combination with HFE-7100. The concentration of DMAB investigate ranged from 0.2 to $1 \mathrm{~g}$ per $100 \mathrm{~mL}$ of solvent, with

55 little variation seen in development quaility. The concentration of DMAB in Ehrlich's Reagent ranges from 0.08 to $1 \mathrm{~g}$ per $100 \mathrm{~mL}$. Hence, it was not surprising to find that the different trialled DMAB concentrations had little effect on the overall fingermark development ${ }^{13,15}$.

${ }_{60}$ The formulation that provided the best results was determined to be a final wet contact working solution of $1 \mathrm{~mL}$ of stock solution (1 g DMAB in $22 \mathrm{~mL}$ ethyl acetate and $3 \mathrm{~mL}$ acetic acid) in $9 \mathrm{~mL}$ HFE-7100. The working solution gave satisfactory fingermark development after one month of storage, with little or ${ }_{65}$ no decrease in reagent performance. However, as DMAB is degraded by UV radiation, the stock solution must be stored in a cabinet, preferably by either using a tinted storage bottle or by wrapping a clear storage bottle in aluminium foil.

Having the optimal reagent formulation does not necessarily 70 result in good fingermark development. Two very important aspects in the treatment stage are the contact time of the reagent with the sample and, if necessary, the application of heat to increase the reaction rate. Some reagents require long contact times to ensure that the complete reaction or staining can take 75 place. However, the longer the contact time, the greater the possibility of removing parts of the fingermark deposits, while possibly not offering significant improvement to the development.

This is especially important if the reagent is to be used in so sequence with other treatment options that may target components that could be washed away by the solvent. The contact time of the sample with the working solution was varied, with a range of 1, 2-3 and 10 seconds, as well as 5 and 10 minutes being trialled. Dipping the samples into the working 85 solution for around 1-2 seconds appeared to offer the best compromise when considering the above factors. 


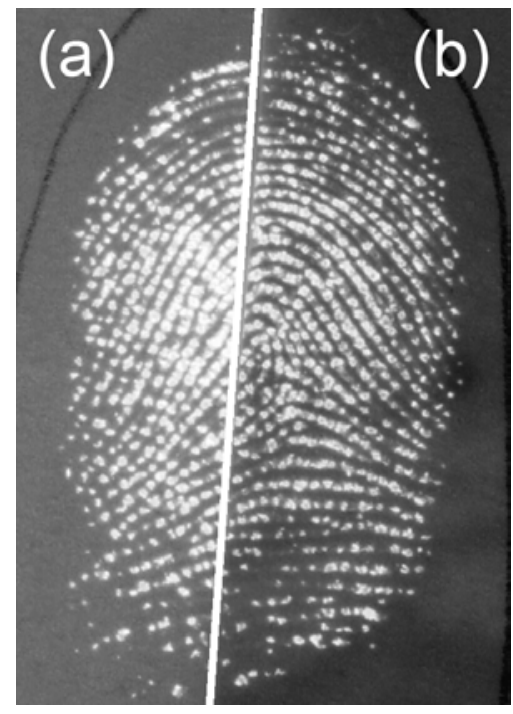

Fig. 4 Fingermark treated with DMAB working solution, (a) heated in an oven and (b) an Elna laundry press. Photograph taken with a Nikon D300 camera in luminescence mode; focal length: $60 \mathrm{~mm}$, shutter speed: 1 second and aperture: f/11.
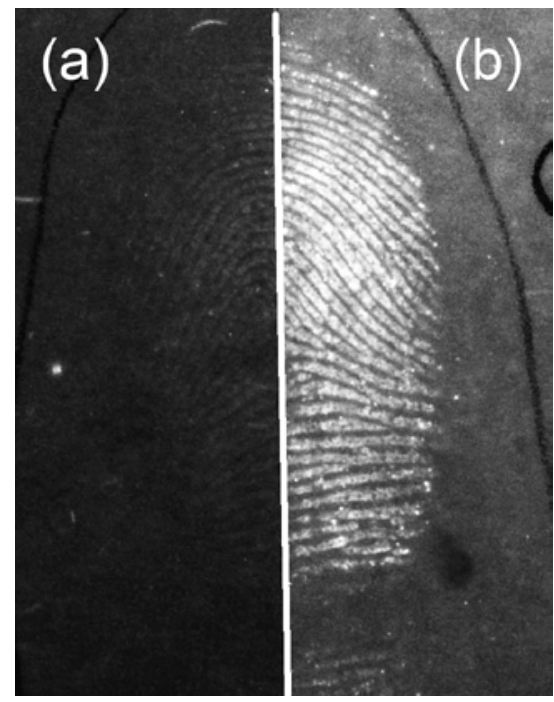

Fig. 5 Fingermark treated with the dry contact DMAB method, (a) left in a zip-lock bag for 2 days and (b) heated using an Elna laundry press. Photograph taken with a Nikon D300 camera in luminescence mode;

The effects of heat to aid the fingermark development were investigated using an Elna laundry press (10, 20, 30, 45 and 60 seconds at low, medium or high $\left(\sim 160{ }^{\circ} \mathrm{C}\right)$ temperature settings) 15 and an oven $(10,20$ or 30 minutes at $75,100,125,150$ or 175 ${ }^{\circ} \mathrm{C}$ ). In the case of the Elna press, heating the treated samples for 20 seconds at $\sim 160{ }^{\circ} \mathrm{C}$ provided the best balance of developing the complex and protecting the paper from charring. Very poor development resulted at lower temperature settings, while shorter 20 heating times (10 seconds) resulted in underdevelopment and long heating times (30 seconds) resulted in the charring of the paper.

For samples placed in an oven, the best balance between development (not occurring at temperatures of $75-125^{\circ} \mathrm{C}$ ) and 25 non-charring of the paper (which occurred at $175^{\circ} \mathrm{C}$ ) was found

to be at $150{ }^{\circ} \mathrm{C}$ for 20 minutes. The results obtained with the oven were comparable to those obtained with the Elna press was more difficult. The oven was more likely to over-develop fingermark samples and give more background development, 30 however it appeared to be slightly more effective for weakly developed samples (Fig. 4).

As substrates may be encountered that cannot be subjected directly to either the solvents or acid contained in the working solution, dry contact methods were also evaluated. This consists 35 of treating blank sheets of either white photocopy paper or filter paper with the reagent, and then placing the sample in between these dried sheets. The approach to developing a dry contact DMAB reagent was followed and adapted from the IND dry contact process developed by Patton et al. ${ }^{22}$. A combination of 40 solvents (ethanol, ethyl acetate, HFE-7100 and petroleum spirits) with glacial acetic acid were investigated as carrier solvents. It was found that while ethyl acetate was again the best solvent, any form of acid in the dry contact formulation inhibited the imine/enamine formation. The effect of the concentration of

${ }_{45}$ DMAB in the working solution was slightly more significant than in the wet contact method, and it was found that both too high and too low concentrations impaired the development. The final working solution consisted of $4 \mathrm{~g}$ of DMAB in $100 \mathrm{~mL}$ ethyl acetate.

50 The dry contact samples were either heat treated using the Elna press (20, 30, 45 or 60 seconds) or in an oven at $150{ }^{\circ} \mathrm{C}$ for 20 minutes. It was found that heating the samples in the oven did not provide the same level of development that the Elna press afforded, with the best results achieved after heating at $\sim 160{ }^{\circ} \mathrm{C}$ ${ }_{55}$ for 45 seconds. However, some samples, such as thermal paper, cannot be exposed to heat. In these cases the sample was placed between treatment papers in plastic zip-lock bags and left for 2 or 6 days in ambient conditions. Samples left for 6 days displayed only slightly more detail than those left for 2 days, and compared 60 to the results of the Elna press, it provided fingermarks with much weaker development (Fig. 5).

\section{Photoluminescence Studies}

In order to investigate whether the DMAB was reacting with the amino acid content of latent fingermark deposits, solutions of 65 amino acids in water (alanine, serine and glycine, at $15 \mu \mathrm{g} / \mu \mathrm{L}$ (high) and $0.15 \mu \mathrm{g} / \mu \mathrm{L}$ (low) concentrations) were deposited $(10 \mu \mathrm{L})$ on paper, dried and then subjected to DMAB development as per latent fingermarks. These amino acids were selected as they have been reported as the most abundant amino 70 acids in latent fingermarks ${ }^{\text {9, } 31}$.

All of the treated high concentration spots appeared as yellowbrown impressions which exhibited strong photoluminescence when illuminated at $490 \mathrm{~nm}$ and viewed through orange filter (Fig. 6). The low concentration spots demonstrating much lower 75 levels of colour and luminescence intensity. 


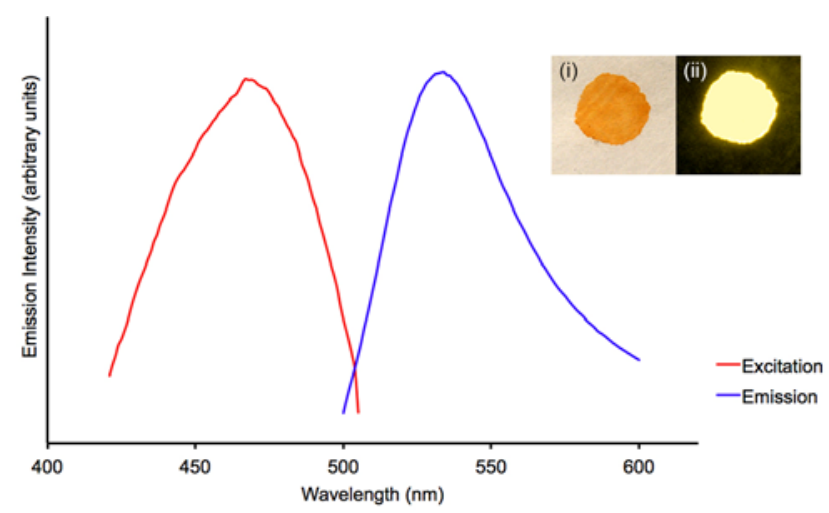

Fig. 6 Luminescence spectra for L-alanine amino acid spots on paper developed with DMAB. Inset image of developed L-alanine spot on paper photographed by Nikon D300 camera,focal length: $60 \mathrm{~mm}$, in (i) absorbance mode; shutter speed: 1/20 second and aperture: f/11 (ii) luminescence mode; shutter speed: 1 second and aperture: f/11

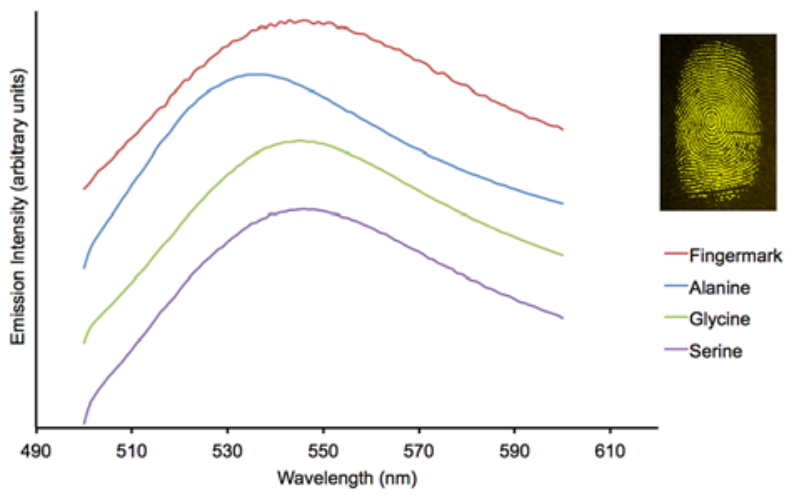

Fig. 7 Luminescence spectra for amino acid spots (L-alanine, glycine and L-serine) and latent fingermark on paper developed with DMAB. Lalanine, glycine, L-serine spot tests, as well as a developed latent fingermark (photograph). Spectra have been normalised and offset to illustrate similarities and differences in shape and maxima. Inset photograph taken with a Nikon D300 camera in luminescence mode; focal length: $60 \mathrm{~mm}$, shutter speed: 1 second and aperture: $\mathrm{f} / 11$.

15 Photoluminescence excitation and emission spectra for the treated high concentration alanine spot is presented in Fig. 6 and the emission spectra of each of the treated amino acid spots and a treated latent fingermark are presented in Fig. 7. Each of the treated amino acids had a similar excitation wavelength of 480 $20 \mathrm{~nm}$. Emission spectra for the treated amino acid spots and latent fingermark were collected using an excitation of $490 \mathrm{~nm}$ (as this matches the available wavelngth on the Polilight). The emission spectra in Fig. 7 show similar maxima except for L-alanine which is shifted by around $15 \mathrm{~nm}$ towards the blue. This would not be 25 surprising as eac amino acid would result in a different imine (see Fig. 1). The values for emission and excitation wavelengths for the DMAB developed amino acids are similar to the values observed by Khalil (excitation at $\sim \mathbf{4 7 5} \mathrm{nm}$ ) and Cessi and Piliego (emission at $545 \mathrm{~nm}$ ), although they used different target 30 nitrogenous compounds ${ }^{15,32}$. The emission spectrum for the developed latent fingermark is very similar to developed amino acids spots indicating that the DMAB is targeting the amino acids in the latent fingermark deposit. The marginal increase in width in the emission peak for the DMAB developed latent fingermark
${ }_{35}$ is likely to be due to the range of amino acids in the fingermark and their relative concentrations.

From an operational point of view, more than $90 \%$ of the excitation and emission is in the range from 473-495 and 527-547 $\mathrm{nm}$, respectively. This corresponds to using a blue-green light 40 source, such as available with the Polilight, with an orange barrier filter and is in fact very similar (and should require no extra instrumentation) to the conditions used for IND treated fingermarks. Although Takatsu et al. indicate that the best visualisation occurs when exciting with a UV-source (at $365 \mathrm{~nm}$ ), 45 due to the optical brighteners used in nearly all paper sources (which make the paper appear more 'white'), this will give rise to a very bright background, thereby greatly reducing the contrast.

\section{Sequencing with other latent fingermark development} methods

50 It is possible to increase the number of developed fingermarks by treating the samples in sequence with different development methods, especially when handling challenging exhibits ${ }^{4}$. This is typically performed using one or two amino acid sensitive reagents, followed by reagents targeting the sebaceous secretions ${ }_{55}{ }^{21}$. This approach not only allows for a greater variety of substrates to be treated, but it is also effective in treating samples that have been subjected to water. DMAB was therefore tested in sequence with other latent fingermark development reagents, where samples were treated with either DMAB or IND/ $\mathrm{ZnCl}_{2}$, 60 followed by ORO and PD (Fig. 8). This sequence also allowed the sensitivity of DMAB to be compared to an amino acid sensitive reagent in current operational use ( $\mathrm{IND} / \mathrm{ZnCl}_{2}$ ).

It was found that the performance on strongly developed impressions is similar with either amino acid sensitive reagent, ${ }_{65}$ however IND/ $\mathrm{ZnCl}_{2}$ provides better visualisation on weak prints. It was noted though that ORO performs much better in sequence on DMAB treated fingermarks, with improved colouration and more detail visible when compared to $\mathrm{IND} / \mathrm{ZnCl}_{2}$. It should be noted that it was found in our previous study that the exposure to 70 non-polar solvents has to be limited to prevent lipid migration to allow the successful application of the ORO reagent ${ }^{33}$. More interestingly, luminescent detail could still be seen, although diminished, on the DMAB treated fingermark following ORO treatment (Fig. 9). This would suggest that the imine/enamine 75 complex is water soluble to a lesser extent than the Joullié's Pink complex formed with IND/ $\mathrm{ZnCl}_{2}$. Both treated fingermark halves reacted to the same extent with $\mathrm{PD}$, with very slightly better development again occurring in sequence with DMAB. And as with ORO, fingermarks that were very strongly developed with 80 DMAB, still offered luminescent detail even after the destructive PD sequence (Fig. 9). 
(a)

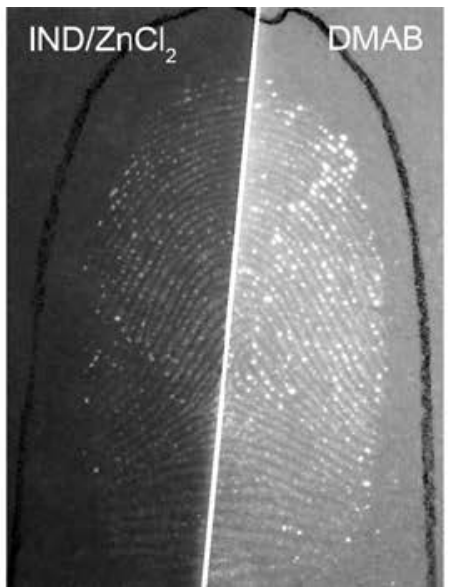

(b)

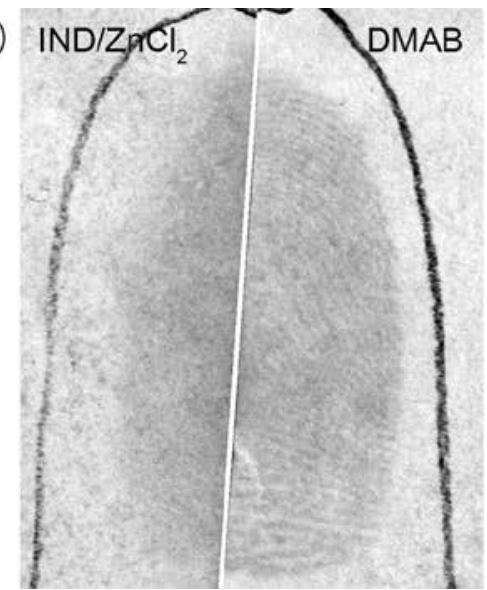

(c)

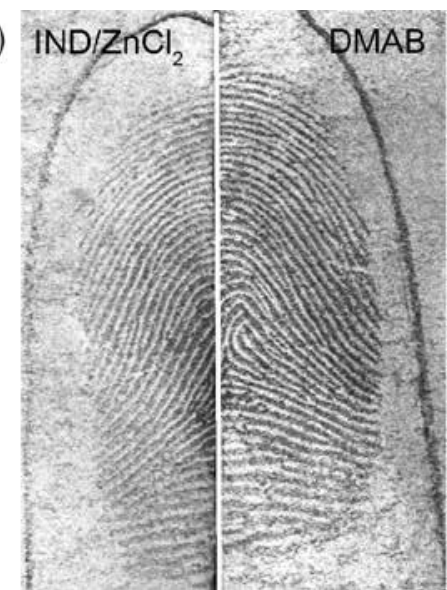

Fig. 8 Charged fingermark sample treated with (a) IND/ $\mathrm{ZnCl}_{2}$ (left-half) or DMAB (right-half), followed by (b) ORO and then (c) PD. Photographs taken with a Nikon D300 camera in luminescence mode (DMAB and IND/ZnCl 2 ); focal length: $60 \mathrm{~mm}$, shutter speed: 1 second and aperture: f/11; and in absorbance mode (ORO and PD); focal length: $60 \mathrm{~mm}$, shutter speed: 1/20 second and aperture: f/11.

(a)

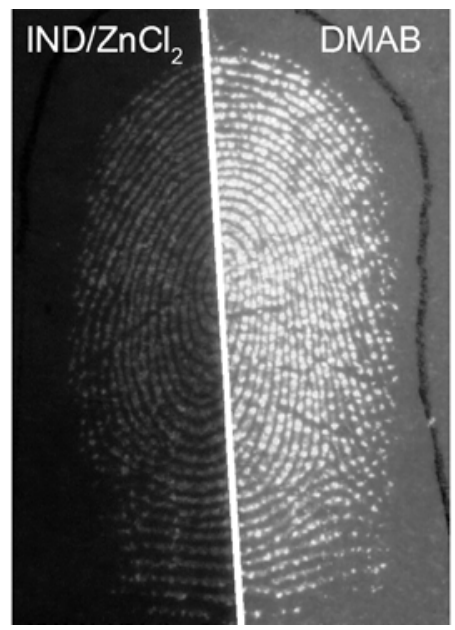

(b)

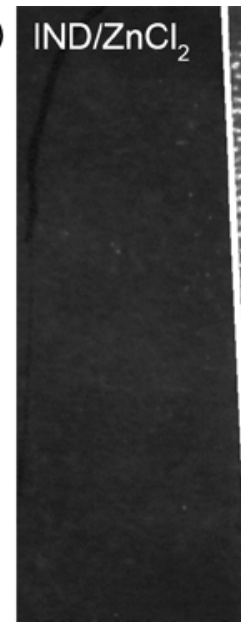

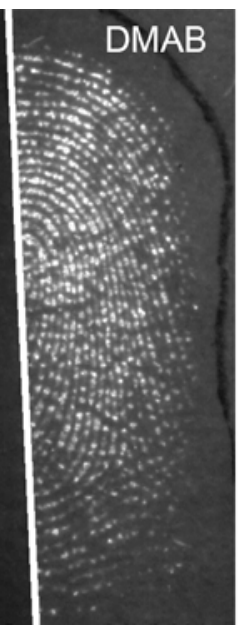

(c)





Fig. 9 Fingermark treated with (a) IND/ZnCl $($ left-half) or DMAB (right-half), followed by (b) ORO and then (c) PD. Photographs taken with a Nikon D300 camera in luminescence mode; focal length: $60 \mathrm{~mm}$, shutter speed: 1 second and aperture: f/11.

\section{Interval between deposition and development}

Sasson and Almog found that DMAC was unable to reliably develop fingermarks older than 72 hours, with the prints being displayed as "unresolved stains" ${ }^{19}$. Latent fingermark deposits are frequently required to be developed at extended periods after 15 deposition. Fingermark deposits that had been left in ambient conditions for extended periods were treated with the final DMAB working method. Interestingly, full detail was still observed in strong fingermarks even after one month, however all samples showed diminished intensity compared to the halves that 20 were developed when fresh. Fingermark samples developed after 3.5 months showed greatly reduced ridge detail, however, there was no blurring of the ridgelines as was the case with the DMAC method (Fig 10). It was noted that the intensity of $\mathrm{IND} / \mathrm{ZnCl}_{2}$ treated latent fingermarks was affected to a a lesser extent than 25 those treated with DMAB.
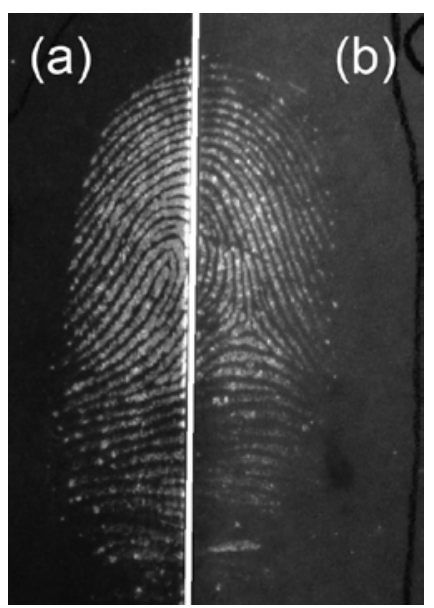

Fig. 10 One month old fingermark treated with (a) IND/ZnCl 2 and (b) DMAB working solution. Photograph taken with a Nikon D300 camera in 30 luminescence mode; focal length: $60 \mathrm{~mm}$, shutter speed: 1 second and aperture: $\mathrm{f} / 11$. 


\section{Conclusions}

These preliminary investigations show that dimethylaminobenzaldehyde (DMAB) can be used as a reagent to develop latent fingermarks on paper surfaces yielding 5 impressions that are both coloured and photoluminescent. The proposed protocols are simple and make use of a widely available, inexpensive, reagent. The wet contact method proved effective on non-fragile porous substrates such as white photocopy paper and various other substrates, whereas the dry 10 contact method afforded development on thermal paper. The final wet contact working method consistedof $1 \mathrm{~mL}$ of stock solution (1 g DMAB in $22 \mathrm{~mL}$ ethyl acetate and $3 \mathrm{~mL}$ acetic acid) in $9 \mathrm{~mL}$ HFE-7100. The sample is then immersed into the working solution for 1-2 seconds before being air dried on paper towels 15 at room temperature, followed by heating in an oven at $150{ }^{\circ} \mathrm{C}$ for 20 minutes. The final dry contact method consisted of either placing the samples between treatment papers (made with a working solution of $4 \mathrm{~g}$ of DMAB in $100 \mathrm{~mL}$ ethyl acetate) in an Elna press at high temperature for 45 seconds (non-fragile 20 samples) or in between treatment papers in a zip-lock bag for 2 days (fragile samples). Photoluminescence is observed by illumination with a high intensity filtered light source at $490 \mathrm{~nm}$ and viewing through an orange barrier filter (OG550). These preliminary results suggest that $\mathrm{IND} / \mathrm{ZnCl}_{2}$ is still the more 25 sensitive technique when dealing with weaker impressions. However, due to DMAB developed marks retaining their luminescent properties after treatment with Oil Red $\mathrm{O}$ and PD, DMAB has improved performance compared to IND/ $\mathrm{ZnCl}_{2}$ when used in sequence with treatments targetting the sebeceous 30 component of latent fingermark deposits. This may be very useful in an operational context when dealing with challenging exhibits 4 .

Further studies are required to more fully investigate the operational potential of DMAB for latent fingermark detection, 35 including a more comprehensive comparison with exisiing amino-acid sensitive treatments. These include studies into a wider range of substrates and the effect of including other components, such as metal salts, in the formulation or as a post treatment. In addition there is a need to synthesis and isolate the 40 photoluminescent reaction products of DMAB and amino acids. Once the properties of these are better understood there is the potential to rationally design and synthese analogues of DMAB that provide improved performance as fingermark detection reagents in a similar fashion to the approach taken with ninhdrin 45 and its analogues ${ }^{4}$.

\section{Acknowledgements}

A. Frick is thanked for her support in the evaluation of the fingermark results. Dr A. Payne is thanked for his help with the reaction mechanism. P. Fritz is supported by an Australian 50 Postgraduate Award. All of the fingermark donors are thanked for their contribution. This study has been approved by the Curtin University Human Research Ethics Committee (Approval Number SMEC-94-11 and SMEC-08-13).

\section{Notes and references}

$55{ }^{a}$ Department of Chemistry, Curtin University, Perth, Western Australia, Australia. Fax: +6189266 2300; Tel: +61 89266 2484; E-mail: S.Lewis@curtin.edu.au

1. C. Champod, C. Lennard, P. Margot and M. Stoilovic, Fingerprints and Other Ridge Skin Impressions, CRC Press, Boca Raton, 2004.

2. R. S. Ramotowaski, ed., Lee and Gaensslen's Advances in Fingerprint Technology, 3rd edn., CRC Press, Boca Raton, 2012.

3. C. Lennard, in Encyclopedia of Analytical Science, eds. P. Worsfold, A. Townshend and C. Poole, Elsevier, Oxford, 2nd edn., 2005, pp. 65 414-423.

4. R. Jelly, E. L. T. Patton, C. Lennard, S. W. Lewis and K. F. Lim, Anal. Chim. Acta, 2009, 652, 128-142.

5. P. F. Kelly, R. S. P. King and R. J. Mortimer, Chemical Communications, 2008, 46, 6111-6113.

70 6. X. Spindler, O. Hofstetter, A. M. McDonagh, C. Roux and C. Lennard, Chem. Commun. (Cambridge, U. K.), 2011, 47.

7. M. Sametband, I. Shweky, U. Banin, D. Mandler and J. Almog, Chemical Communications, 2007, 11, 1142-1144.

8. R. Jelly, S. W. Lewis, C. Lennard, K. F. Lim and J. Almog, Chem. 75 Commun. (Cambridge, U. K.), 2008, 3513-3515.

9. A. A. Frick, P. Fritz and S. W. Lewis, in Encyclopedia of Forensic Sciences, eds. J. A. Siegel and P. J. Saukko, 2 edn., 2013, pp. 92-97.

10. D. B. Hansen and M. M. Joullie, Chem. Soc. Rev., 2005, 34, 408-417.

11. D. B. Hauze, O. Petrovskaia, B. Taylor, M. M. Joullie, R.

80 Ramotowski and A. A. Cantu, Journal of Forensic Sciences, 1998, 43, 744-747.

12. S. Merrick, S. J. Gardner, V. G. Sears and D. F. Hewlett, Journal of Forensic Identification, 2002, 52, 595.

13. W. H. Waugh and P. T. Beall, Kidney International, 1974, 5, 42985436.

14. C. W. Easley, Biochim. Biophys. Acta, 1965, 107, 386-388.

15. C. Cessi and F. Piliego, Biochemical Journal, 1960, 77, 508-510.

16. C. W. M. Adams, Journal of Clinical Pathology, 1957, 10, 56-62.

17. O. A. Adegoke, International Journal of Pharmaceutical Sciences 90 Review and Research, 2011, 11, 17-29.

18. Morris, J. R., British Patent 14230251976.

19. Y. Sasson and J. Almog, Journal of Forensic Sciences, 1978, 23, 852-855.

20. M. Takatsu, O. Shimoda and H. Teranishi, Journal of Forensic $95 \quad$ Sciences, 2012, 57, 515-520.

21. M. Stoilovic and C. Lennard, AFP Workshop Manual: Fingerprint Detection and Enhancement, 3rd edn., Forensic Services, Australian Federal Police, Canberra, 2006.

22. E. L. T. Patton, D. H. Brown and S. W. Lewis, Analytical Methods, $100 \quad 2010,2,631-637$.

23. X. Spindler, M. Stoilovic, C. Lennard and A. Lennard, Journal of Forensic Identification, 2009, 59, 308-324.

24. A. A. Frick, P. Fritz, S. W. Lewis and W. van Bronswijk, Journal of Forensic Identification, 2012, 62, 623-641.

105 25. G. Sauzier, A. A. Frick and S. W. Lewis, Journal of Forensic Identification (in press), 2012.

26. J. Salama, S. Aumeer-Donovan, C. Lennard and C. Roux, Journal of Forensic Identification, 2008, 58, 203-237.

27. G. T. W. Solomons, in Organic Chemistry, eds. G. T. W. Solomons $110 \quad$ and C. B. Fryhle, John Wiley \& Sons, Inc., 7 edn., 2000. 
28. J. McMurray, in Organic Chemistry, ed. S. Kiselica, Brooks/Cole, Belmont, California, 6th edn., 2004.

29. O. A. Adegoke and C. E. Nwoke, Journal Of The Iranian Chemical Society, 2008, 5, 316-323.

5 30. C. Wallace-Kunkel, C. Lennard, M. Stoilovic and C. Roux, Forensic Science International, 2007, 168, 14-26.

31. K. Alaa, Journal of Chromatography B, 2010, 878, 1576-1582.

32. R. A. Khalil and S. A. Hussain, The Arabian Journal for Science and Engineering, 2010, 35, 55-66.

10 33. A. A. Frick, P. Fritz, S. W. Lewis and W. van Bronswijk, Journal Forensic Identification (in Press), 2013. 